\title{
Voltage Mode Cascadable All-Pass Sections Using Single Active Element and Grounded Passive Components
}

\author{
Jitendra Mohan $^{1^{*}}$, Sudhanshu Maheshwari ${ }^{2}$, Durg S. Chauhan ${ }^{3}$ \\ ${ }^{1}$ Department of Electronics and Communications, Jaypee University of Information Technology, \\ Solan, India \\ ${ }^{2}$ Department of Electronics Engineering, Z. H. College of Engineering and Technology, \\ Aligarh Muslim University, Aligarh, India \\ ${ }^{3}$ Department of Electrical Engineering, Institute of Technology, Banaras Hindu University, \\ Varanasi, India \\ E-mail: jitendramv2000@rediffmail.com \\ Received April 23, 2010; revised May 27, 2010; accepted June 2, 2010
}

\begin{abstract}
In this paper, four new first order voltage mode cascadable all-pass sections are proposed using single active element and three grounded passive components, ideal for IC implementation. The active element used is a fully differential current conveyor. All the proposed circuit possess high input and low output impedance feature which is a desirable feature for voltage-mode circuits. Non-ideality aspects and parasitic effects are also given. As an application, a multiphase oscillator is designed. The proposed circuits are verified through PSPICE simulation results using TSMC $0.35 \mu \mathrm{m}$ CMOS parameters.
\end{abstract}

Keywords: Analogue Signal Processing, All-Pass Filter, Current Conveyor, Voltage-Mode

\section{Introduction}

Voltage mode (VM) active filters with high-input and low-output impedance are of great interest because several cells of this kind can be directly connected in cascade within voltage-mode systems without additional voltage buffers. On the other hand, the use of grounded capacitor is beneficial from the point of integrated circuit implementation and also having less parasitic compared to floating counterparts [1].

First order all-pass filters are an important class of analogue signal processing circuits which have been extensively researched in the technical literature [2,3] due to their utility in communication and instrumentation systems, for instance as a phase equalizer, phase shifter or for realizing quadrature oscillators band pass filters etc. Numerous first-order voltage-mode all-pass sections (VMAPSs) employing different types of active element such as current conveyors and its different variations have been reported in the literature [4-24]. Among the cited references, several VM-APSs employ a single standard current conveyor [6-16,19-22]. Such circuits aim at realizing the first order all-pass function using optimum number of passive components, rather using grounded components or offering high input and low output impedance feature together. The circuits reported in [17,18] enjoy high input impedance but uses two active element and three grounded passive components. Some of the circuits described in [15,21-23] fall in the separate category of tunable, resistorless realizations, the most recent of these $[22,23]$ enjoys high input and/or low output impedance. A recent published all-pass filter circuit in [24] employ two DVCCs and two passive components with the advantage of high input impedance and low output impedance, which is ideal for cascading, but it still suffer from floating resistor. But a careful survey reveals that none of the reported works realizes a VM-APS using single active element, grounded passive components, and also providing high input impedance and low output impedance features simultaneously.

This paper proposes four new first order VM cascadable all-pass sections, with high input and low output impedance using single active element and three grounded passive components, which are ideal for IC implementation. Each circuit employs two grounded resistors and one grounded capacitor. The proposed circuits are based on fully differential second generation current conveyor (FDCCII), an active element to improve the dynamic range in mixed mode application, where fully differential signal processing is required [25]. As an application, the 
proposed circuit realizes a multiphase oscillator. PSPICE simulation results using TSMC $0.35 \mu \mathrm{m}$ CMOS parameters are given to validate the circuits.

The paper is organized as follows: in Section 2, the proposed all-pass filters using FDCCII are presented. In Section 3, parasitic and non-ideal analyses of the proposed circuits are given. In Section 4, to verify the theoretical study the first order all-pass filters were constructed and simulated with PSPICE program. In Section 5, a multi- phase oscillator is implemented to show the usefulness of the proposed circuits as an illustrating example and finally the conclusion in Section 6.

\section{Proposed Circuit}

The FDCCII is an eight terminal analog building block with a describing matrix equation of the form [25]

$$
\left[\begin{array}{c}
I_{Y 1} \\
I_{Y 2} \\
I_{Y 3} \\
I_{Y 4} \\
V_{X+} \\
V_{X-} \\
I_{Z+} \\
I_{Z-}
\end{array}\right]=\left[\begin{array}{cccccccc}
0 & 0 & 0 & 0 & 0 & 0 & 0 & 0 \\
0 & 0 & 0 & 0 & 0 & 0 & 0 & 0 \\
0 & 0 & 0 & 0 & 0 & 0 & 0 & 0 \\
0 & 0 & 0 & 0 & 0 & 0 & 0 & 0 \\
1 & -1 & 1 & 0 & 0 & 0 & 0 & 0 \\
-1 & 1 & 0 & 1 & 0 & 0 & 0 & 0 \\
0 & 0 & 0 & 0 & 1 & 0 & 0 & 0 \\
0 & 0 & 0 & 0 & 0 & 1 & 0 & 0
\end{array}\right]\left[\begin{array}{l}
V_{Y 1} \\
V_{Y 2} \\
V_{Y 3} \\
V_{Y 4} \\
I_{X+} \\
I_{X-} \\
V_{Z+} \\
V_{Z-}
\end{array}\right]
$$

The symbol and CMOS implementation of FDCCII are shown in Figure 1 [25]. The $Y_{1}, Y_{2}, Y_{3}$, and $Y_{4}$ terminals are high-impedance terminals, while $X+$ and $X$ - terminals are low-impedance ones. The $Z+$ and $Z$ - terminals are high impedance nodes suitable for current outputs. FDCCII is a useful and versatile active element for analog signal processing. The applications of FDCCIIs in filters and oscillators design using only grounded passive components were demonstrated in [26,27].

The voltage transfer function of an all-pass filter can be given as

$$
\frac{V_{\text {OUT }}}{V_{I N}}=K \frac{s \tau-1}{s \tau-1}
$$

where $K$ is the gain constant and its sign determines whether phase shifting is from $0^{\circ}$ to $-180^{\circ}$ or from $180^{\circ}$ to $0^{\circ}$, and $\tau$ is the time constant. The four proposed first order VM cascadable all-pass sections using a single FDCCII and three grounded passive components are shown in Figures 2(a)-2(d). The four circuits in Figures 2 (a)-2(d) are characterized by the voltage transfer function as

$$
\frac{V_{\text {OUT }}}{V_{I N}}=K\left(\frac{s-\left(1 / C_{1}\right)\left[\left(1 / R_{2}\right)-\left(1 / R_{1}\right)\right]}{s+\left(1 / R_{1} C_{1}\right)}\right)
$$

For $R_{2}=R_{1} / 2$ Equation (3) becomes

$$
\frac{V_{\text {OUT }}}{V_{I N}}=K \frac{s R_{1} C_{1}-1}{s R_{1} C_{1}+1}
$$

where the value of $K=+1$ for Circuit-I and Circuit-II (Figures 2(a) and 2(b)) and the value of $K=-1$ for Circuit-III and Circuit-IV (Figures 2 (c) and 2(d)).

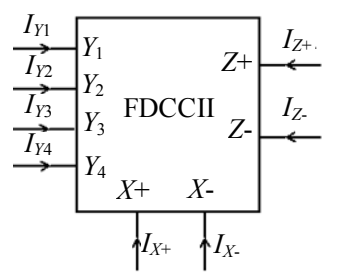

(a)

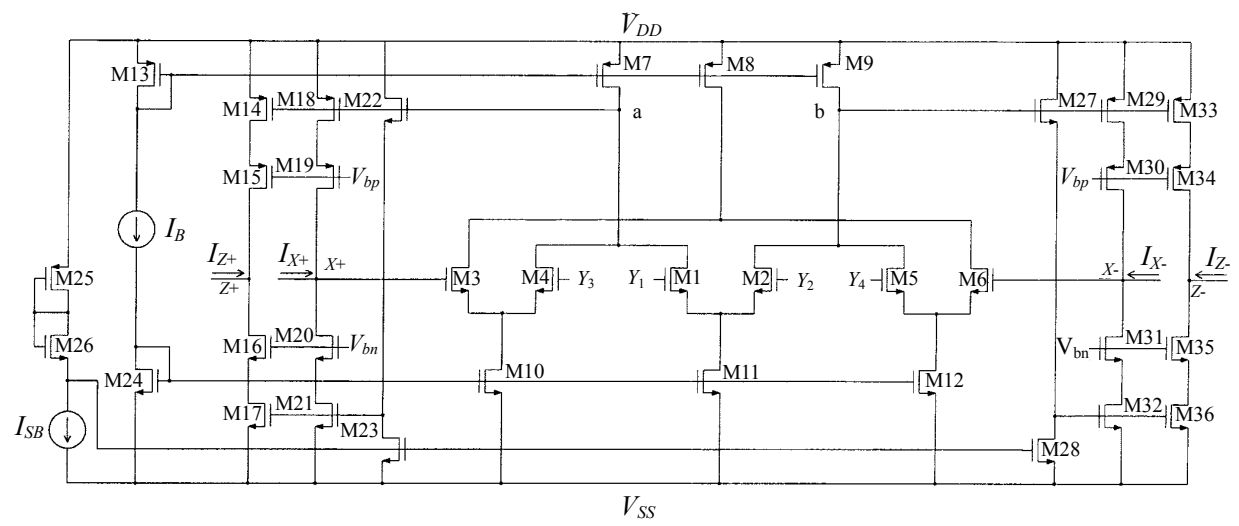

(b)

Figure 1. Fully differential second generation current conveyor (a) symbol (b) CMOS implementation [25]. 


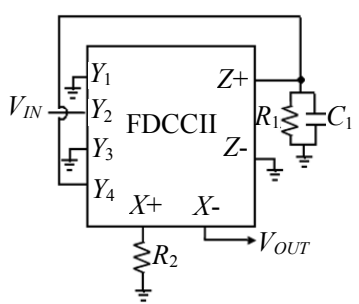

(a)

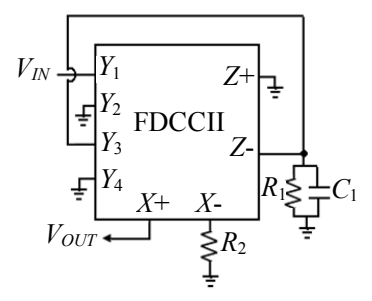

(b)

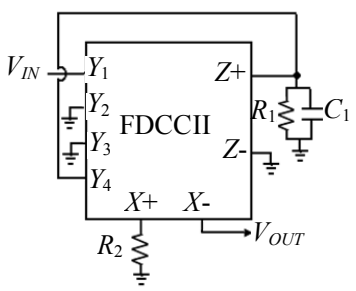

(c)

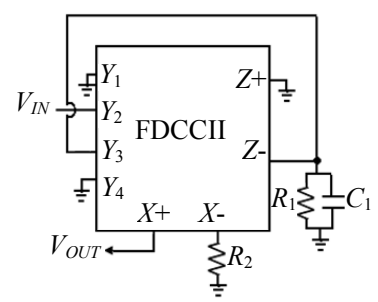

(d)

Figure 2. Proposed first order cascadable all-pass filters (a) circuit-I; (b) circuit-II; (c) circuit-III and (d) circuit-IV.

The salient features of the four proposed circuits are high input and low output impedance, single active element and use of grounded passive components; the three features are not exhibited together in any of the available works, including the most recent circuits [4-24]. It may be noted that the new circuits are based on a topology with input at $Y$ and output at one of the $X$ terminals, the other $X$-terminal being terminated by a resistor. The four proposed circuits with similar properties being derivable from a topology are a result of the versatility of FDCCII.

It is also worth mentioning that four additional new circuits can further be obtained from the proposed circuits by replacing the resistor $\left(R_{2}\right)$ with a capacitor $\left(C_{2}\right)$. However these circuits would employ a capacitor at $X$ terminal, thus degrading high frequency operation. This aspect will not be further elaborated for brevity reasons.

\section{Parasitic and Non-Ideal Analysis}

\subsection{Parasitic Effects}

A study is next carried out on the effects of various parasitic of the FDCCII used in the proposed circuits. These are port $Z$ parasitic in form of $R_{Z} / / C_{Z}$, port $Y$ parasitic in form of $R_{Y} / / C_{Y}$ and port $X$ parasitic in form of series resistance $R_{X}$ [13]. The proposed circuits are reanalyzed taking into account the above parasitic effects. The voltage transfer function (assuming $R<<R_{Y}$ or $R_{Z}$ and $R_{X}<<$ $R$ ), for the circuits of Figures 2(a)-2(d), is given as

$$
\frac{V_{\text {OUT }}}{V_{I N}}=K\left(\frac{s-\left(1 /\left(C_{1}+C_{P}\right)\right)\left[\left(1 / R^{\prime}\right)-\left(1 / R_{1}\right)\right]}{s+\left(1 / R_{1}\left(C_{1}+C_{P}\right)\right)}\right)
$$

where, $R^{\prime}=R_{2}+R_{X}$, (for Figures 2(a)-2(d)), $K=+1$, (for Figures 2(a) and 2(b)), $K=-1$, (for Figures 2(c) and 2(d)), and $C_{P}=C_{Z^{+}}+C_{Y 4}$ (for Figures 2(a) and 2(c)), and $C_{P}=C_{Z-}+C_{Y 3}$ (for Figures 2(b) and 2(d)).

From (5), it is seen that the gain is unity and the pole-frequency is

$$
\omega_{o}=\frac{1}{R_{1}\left(C_{1}+C_{P}\right)}
$$

From (5), the parasitic resistance/capacitances merge with the external value. Such a merger does cause slight deviation in circuit's parameters, which can be eliminated by pre-distorting the element values to be used in the circuit. It is seen that the pole-frequency would be slightly deviated (in deficit) due to these parasitics. The deviation is expected to be small for an integrated FDCCII; the actual value would be given in the 'simulation results'.

\subsection{Non-Ideal Analysis}

Taking the non-idealities of the FDCCII into account, the relationship of the terminal voltages and currents can be rewritten as

$$
\left[\begin{array}{c}
I_{Y 1} \\
I_{Y 2} \\
I_{Y 3} \\
I_{Y 4} \\
V_{X+} \\
V_{X-} \\
I_{Z+} \\
I_{Z-}
\end{array}\right]=\left[\begin{array}{cccccccc}
0 & 0 & 0 & 0 & 0 & 0 & 0 & 0 \\
0 & 0 & 0 & 0 & 0 & 0 & 0 & 0 \\
0 & 0 & 0 & 0 & 0 & 0 & 0 & 0 \\
0 & 0 & 0 & 0 & 0 & 0 & 0 & 0 \\
\beta_{1} & -\beta_{2} & \beta_{3} & 0 & 0 & 0 & 0 & 0 \\
-\beta_{4} & \beta_{5} & 0 & \beta_{6} & 0 & 0 & 0 & 0 \\
0 & 0 & 0 & 0 & \alpha_{1} & 0 & 0 & 0 \\
0 & 0 & 0 & 0 & 0 & \alpha_{2} & 0 & 0
\end{array}\right]\left[\begin{array}{c}
V_{Y 1} \\
V_{Y 2} \\
V_{Y 3} \\
V_{Y 4} \\
I_{X+} \\
I_{X-} \\
V_{Z+} \\
V_{Z-}
\end{array}\right]
$$

where $\alpha_{i}(i=1,2)$ accounts for current transfer gains and $\beta_{i}(i=1,2,3,4,5,6)$ accounts for voltage transfer gains of the FDCCII. These transfer gains differ from unity by the voltage and current tracking errors of the FDCCII. More specifically, $\alpha_{i}=1-\delta_{i},\left(\left|\delta_{i}\right|<<1\right) \delta_{1}$ is the current tracking error from $X+$ to $Z+$ and $\delta_{2}$ is the current tracking error from $X$ - to $Z$-. Similarly, $\beta_{i}=1-\varepsilon_{i},\left(\left|\varepsilon_{i}\right|<<1\right)$ where, voltage tracking errors are $\varepsilon_{1}$ (from $Y_{1}$ to $X+$ ), $\varepsilon_{2}$ (from $Y_{2}$ to $X^{+}$), $\varepsilon_{3}$ (from $Y_{3}$ to $X^{+}$), $\varepsilon_{4}$ (from $Y_{1}$ to $X-$ ), $\varepsilon_{5}$ (from $Y_{2}$ to $X$-), and $\varepsilon_{6}$ (from $Y_{4}$ to $X-$ ). The circuits of Figures 2(a)-2(d) are reanalyzed using (7) and the non-ideal voltage transfer functions are found as

Circuit-I:

$$
\frac{V_{\text {OUT }}}{V_{I N}}=\beta_{5}\left(\frac{s-\left[\left(\alpha_{1} \beta_{2} \beta_{6} R_{1}-\beta_{5} R_{2}\right) / \beta_{5} C_{1} R_{1} R_{2}\right]}{s+\left(1 / C_{1} R_{1}\right)}\right)
$$

Circuit-II: 


$$
\frac{V_{\text {OUT }}}{V_{I N}}=\beta_{1}\left(\frac{s-\left[\left(\alpha_{2} \beta_{3} \beta_{4} R_{1}-\beta_{1} R_{2}\right) / \beta_{1} C_{1} R_{1} R_{2}\right]}{s+\left(1 / C_{1} R_{1}\right)}\right)
$$

Circuit-III:

$$
\frac{V_{\text {OUT }}}{V_{I N}}=-\beta_{4}\left(\frac{s-\left[\left(\alpha_{1} \beta_{1} \beta_{6} R_{1}-\beta_{4} R_{2}\right) / \beta_{4} C_{1} R_{1} R_{2}\right]}{s+\left(1 / C_{1} R_{1}\right)}\right)(10)
$$

Circuit-IV:

$$
\frac{V_{\text {OUT }}}{V_{I N}}=-\beta_{2}\left(\frac{s-\left[\left(\alpha_{2} \beta_{3} \beta_{5} R_{1}-\beta_{2} R_{2}\right) / \beta_{2} C_{1} R_{1} R_{2}\right]}{s+\left(1 / C_{1} R_{1}\right)}\right)
$$

From (8)-(11), it is seen that the pole-frequency is unaltered by FDCCII non-idealities for all the transfer functions of the respective circuit, but the filters gain are slightly modified due to the FDCCII non-idealities. Thus the pole-frequency sensitivity to the FDCCII nonidealities is zero, and the filters gain sensitivity to these nonidealities is found within unity in magnitude. This suggests a good sensitivity performance for the proposed circuits.

\section{Simulation Results}

To verify theoretical result the proposed filter circuits were simulated by the PSPICE simulation program. The FDCCII was realized based on the CMOS implementation as shown in Figure 1 [25] and simulated using TSMC $0.35 \mu \mathrm{m}$, level 3 MOSFET parameters as listed in Table 1. The aspect ratio of the MOS transistors are listed in Table 2, with the following DC biasing levels $V_{d d}=$ $-V_{s s}=3.3 \mathrm{~V}, V_{b p}=V_{b n}=0 \mathrm{~V}$, and $I_{B}=I_{S B}=1.7 \mathrm{~mA}$. The

\begin{tabular}{|c|}
\hline NMOS: \\
\hline LEVEL $=3 \quad$ TOX $=7.9 \mathrm{E}-9 \quad \mathrm{NSUB}=1 \mathrm{E} 17$ \\
\hline GAMMA $=0.5827871 \quad$ PHI $=0.7 \quad \mathrm{VTO}=0.5445549 \quad$ DELTA $=0$ \\
\hline $\mathrm{UO}=436.256147 \quad \mathrm{ETA}=0 \quad \mathrm{THETA}=0.1749684$ \\
\hline $\mathrm{KP}=2.055786 \mathrm{E}-4 \quad \mathrm{VMAX}=8.309444 \mathrm{E} 4 \quad \mathrm{KAPPA}=0.2574081$ \\
\hline $\mathrm{RSH}=0.0559398 \quad \mathrm{NFS}=1 \mathrm{E} 12 \quad \mathrm{TPG}=1 \quad \mathrm{XJ}=3 \mathrm{E}-7$ \\
\hline $\mathrm{LD}=3.162278 \mathrm{E}-11 \quad \mathrm{WD}=7.04672 \mathrm{E}-8 \quad \mathrm{CGDO}=2.82 \mathrm{E}-10$ \\
\hline $\mathrm{CGSO}=2.82 \mathrm{E}-10 \quad \mathrm{CGBO}=1 \mathrm{E}-10 \quad \mathrm{CJ}=1 \mathrm{E}-3 \quad \mathrm{~PB}=0.9758533$ \\
\hline $\mathrm{MJ}=0.3448504 \quad \mathrm{CJSW}=3.777852 \mathrm{E}-10 \quad \mathrm{MJSW}=0.3508721$ \\
\hline PMOS: \\
\hline $\mathrm{LEVEL}=3 \quad$ TOX $=7.9 \mathrm{E}-9 \quad \mathrm{NSUB}=1 \mathrm{E} 17$ \\
\hline GAMMA $=0.4083894 \quad \mathrm{PHI}=0.7 \quad \mathrm{VTO}=-0.7140674$ \\
\hline $\mathrm{DELTA}=0 \quad \mathrm{UO}=212.2319801 \quad \mathrm{ETA}=9.999762 \mathrm{E}-4$ \\
\hline THETA $=0.2020774 \quad \mathrm{KP}=6.733755 \mathrm{E}-5 \quad \mathrm{VMAX}=1.181551 \mathrm{E} 5$ \\
\hline $\mathrm{KAPPA}=1.5 \quad \mathrm{RSH}=30.0712458 \quad \mathrm{NFS}=1 \mathrm{E} 12 \quad \mathrm{TPG}=-1$ \\
\hline $\mathrm{XJ}=2 \mathrm{E}-7 \quad \mathrm{LD}=5.000001 \mathrm{E}-13 \quad \mathrm{WD}=1.249872 \mathrm{E}-7$ \\
\hline $\mathrm{CGDO}=3.09 \mathrm{E}-10 \quad \mathrm{CGSO}=3.09 \mathrm{E}-10 \quad \mathrm{CGBO}=1 \mathrm{E}-10$ \\
\hline $\mathrm{CJ}=1.419508 \mathrm{E}-3 \quad \mathrm{~PB}=0.8152753 \quad \mathrm{MJ}=0.5$ \\
\hline $\mathrm{CJSW}=4.813504 \mathrm{E}-10 \quad \mathrm{MJSW}=0.5$ \\
\hline
\end{tabular}
circuit-I (Figure 2(a)) was designed with $C_{1}=50 \mathrm{pF}$,

Table 1. $0.35 \mu \mathrm{m}$ level 3 MOSFET parameters.
$R_{1}=2 \mathrm{k} \Omega$ and $R_{2}=1 \mathrm{k} \Omega$. The theoretical designed pole frequency was $1.59 \mathrm{MHz}$. The phase and gain plots are shown in Figure 3. The phase is found to vary with frequency from $180^{\circ}$ to $0^{\circ}$ with a value of $90^{\circ}$ at the pole frequency, and the pole frequency was found to be $1.54 \mathrm{MHz}$, which is close to the theoretical value. The circuit was next used as a phase shifter introducing $90^{\circ}$ shift to a sinusoidal voltage input of 1 Volt peak at $1.59 \mathrm{MHz}$. The input and output waveforms are given in Figure 4 which verify the circuit as a phase shifter. The THD variation at the output for varying signal amplitude at $1.59 \mathrm{MHz}$ was also studied and the results shown in Figure 5. The THD for a wide signal amplitude (few $\mathrm{mV}-1 \mathrm{~V}$ ) variation is found within $4.27 \%$ at $1.59 \mathrm{MHz}$. The Fourier spectrum of the output signal, showing a high selectivity for the applied signal frequency $(1.59 \mathrm{MHz})$ is also shown in Figure 6. Both theoretical and simulated pole frequencies are found to closely match; the discrepancy (deficit) in simulated frequency being the result of various parasitic discussed in Section 3.

Table 2. Transistor aspect ratios for the circuit shown in Figure 1.

\begin{tabular}{lcc}
\hline \multicolumn{1}{c}{ Transistors } & $\mathrm{W}(\mu \mathrm{m})$ & $\mathrm{L}(\mu \mathrm{m})$ \\
\hline M1-M6 & 60 & 4.8 \\
M7-M9, M13 & 480 & 4.8 \\
M10-M12, M24 & 120 & 4.8 \\
M14,M15,M18,M19,M25,M29,M30,M33,M34 & 240 & 2.4 \\
M16,M17,M20,M21,M26,M31,M32,M35,M36 & 60 & 2.4 \\
M22,M23,M27,M28 & 4.8 & 4.8 \\
\hline
\end{tabular}

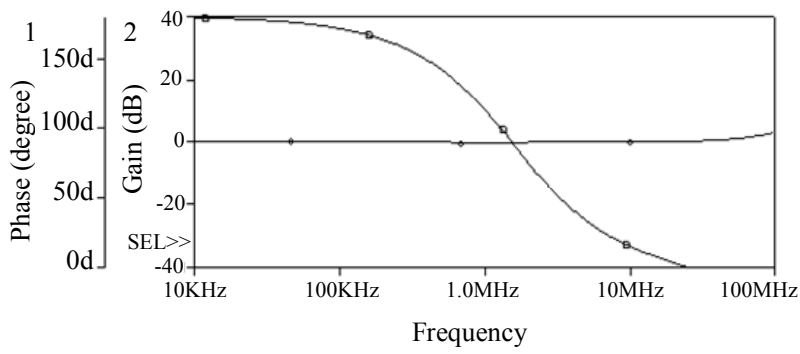

Figure 3. Gain and phase responses for the circuit-I.

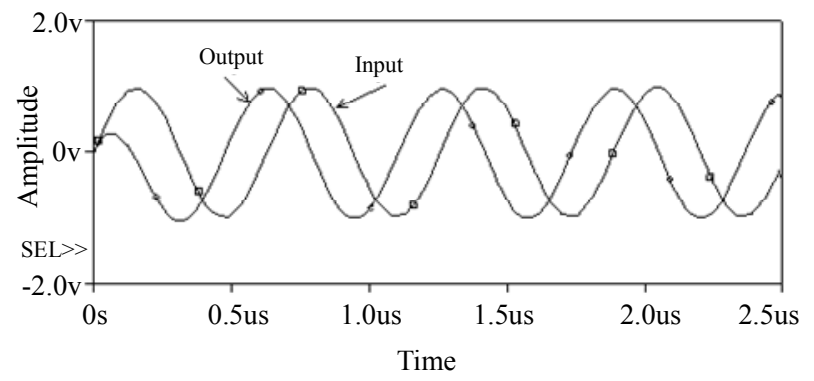

Figure 4. Input/output waveshapes for Circuit-I at 1.59 MHz. 


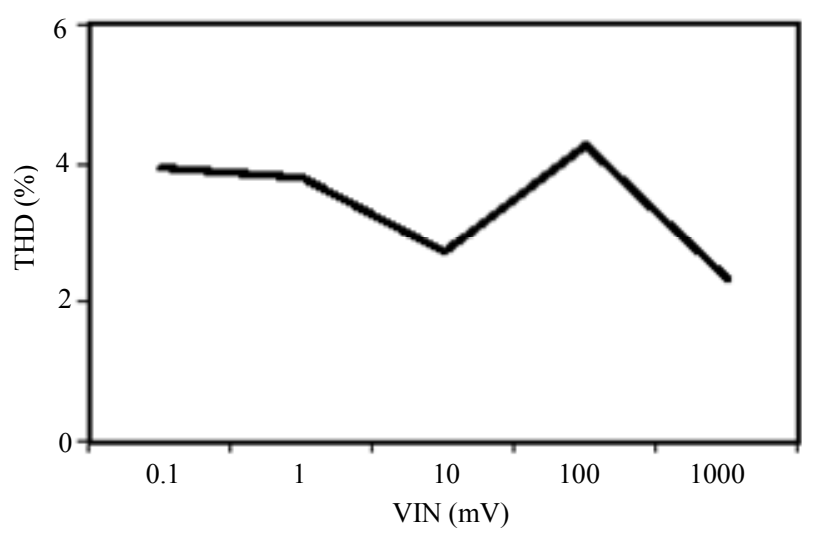

Figure 5. THD variation at output with signal amplitude at 1.59 MHz.

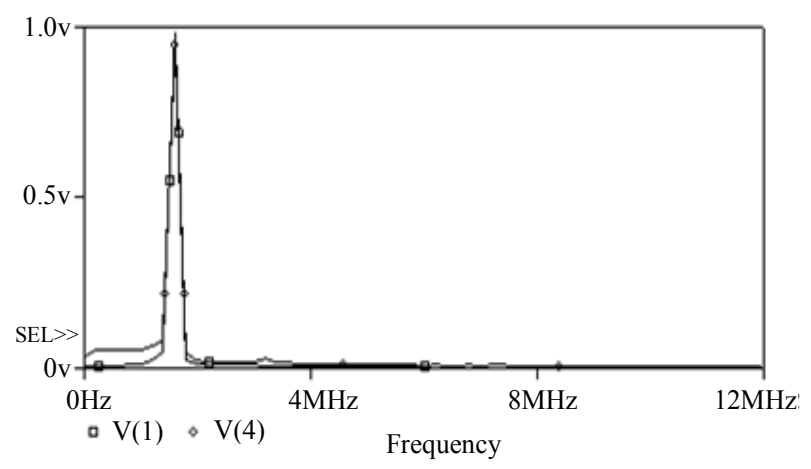

Figure 6. Fourier spectrum of Input-output signal at 1.59 MHz.

Similarly, the circuit-III (Figure 2(c)) was designed with the same values and frequency as above. The phase and gain plots are shown in Figure 7. The phase is found to vary with frequency from 0 to $-180^{\circ}$ with a value of $-90^{\circ}$ at the pole frequency, and the pole frequency was found to be $1.54 \mathrm{MHz}$, which is close to the theoretical value. The circuit was next used as a phase shifter introducing $-90^{\circ}$ shift to a sinusoidal voltage input of 1 Volt peak at $1.59 \mathrm{MHz}$. The input and output waveforms are given in Figure 8 which verify the circuit as a phase shifter.

\section{Application Example}

To further illustrate the utility of the proposed circuits a sinusoidal oscillator producing a number of quadrature signals was realized using the Circuit-I (Figure 2(a)). By connecting $Y_{2}$ terminal, the input node to the $Z$-terminal of FDCCII, connecting resistor $\left(R^{\prime}\right)$ and capacitor $\left(C^{\prime}\right)$ at $X-$ and $Z$ - terminals of FDCCII. The resulting circuit is shown in Figure 9. The circuit analysis yields the following characteristic equation

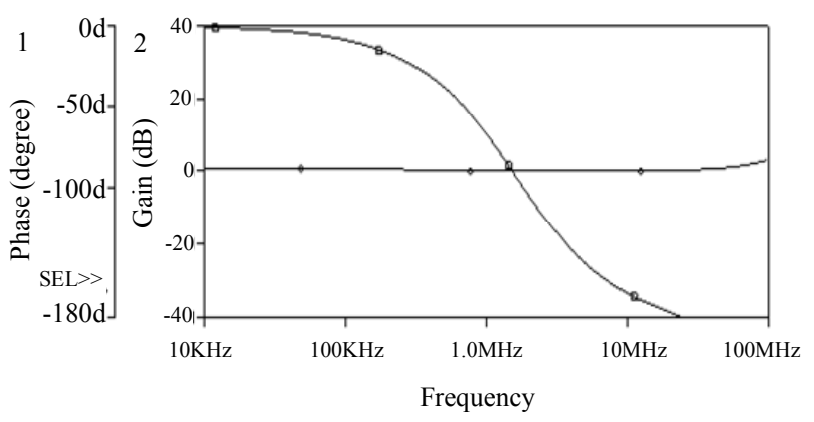

Figure 7. Gain and phase responses for the circuit-III.

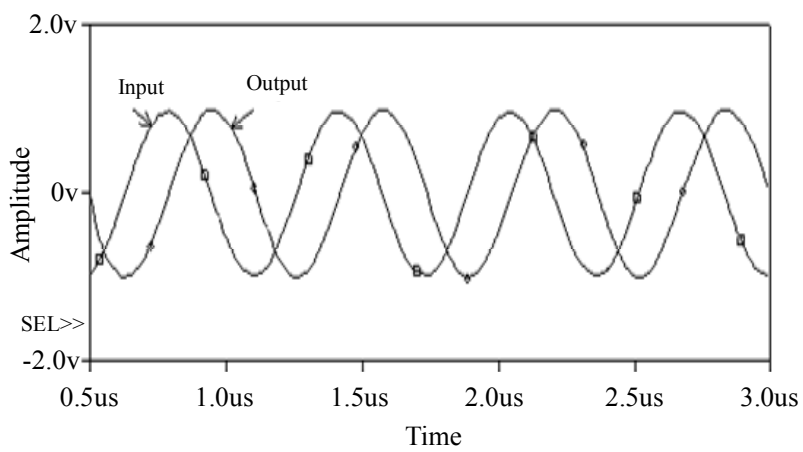

Figure 8. Input/output waveshapes for Circuit-III at 1.59 MHz.

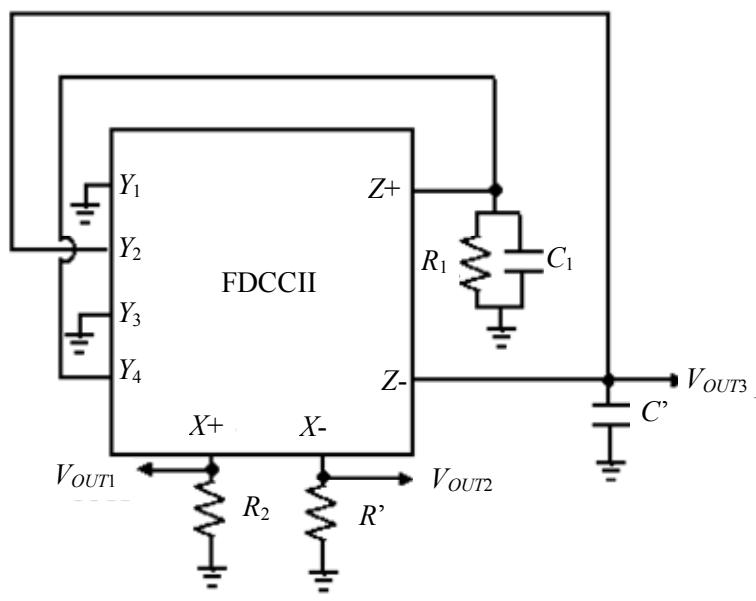

Figure 9. Multiphase oscillator using Circuit-I of Figure 2(a).

$$
s^{2}+s\left[\frac{1}{C_{1} R_{1}}-\frac{1}{C^{\prime} R^{\prime}}\right]+\frac{R_{1}-R_{2}}{C_{1} C^{\prime} R_{1} R_{2} R^{\prime}}=0
$$

At the frequency of oscillation, with $s=j \omega$, the Equation (5) gives the frequency of oscillation $(F O)$ and condition of oscillation $(C O)$ as

$$
F O: \omega_{O}=\sqrt{\frac{R_{1}-R_{2}}{C_{1} C^{\prime} R_{1} R_{2} R^{\prime}}} ; C O: C^{\prime} R^{\prime} \geq C_{1} R_{1}
$$

Assuming $R^{\prime}=R_{1}=2 R_{2} ; C^{\prime}=C_{1}$ 


$$
F O: \omega_{O}=\frac{1}{2 C^{\prime} R^{\prime}}
$$

From Figure 9, at oscillating frequency the circuit provides three quadrature voltage outputs $\left(V_{\text {OUT1 }}, V_{\text {OUT2 }}\right.$ and $\left.V_{\text {OUT3 }}\right)$ whose phasor relationship is shown in Figure 10.

The circuit was designed with $C_{1}=C^{\prime}=50 \mathrm{pF}, R_{1}=R^{\prime}$ $=2 \mathrm{k} \Omega$, and $R_{2}=1 \mathrm{k} \Omega$, the theoretical frequency of oscillation was around $f_{o}=1.59 \mathrm{MHz}$, whereas the simulated values as found from the result was $f_{o}=1.54 \mathrm{MHz}$. The quadrature oscillations are shown in Figure 11.

\section{Conclusions}

This paper has presented four new first-order VM cascadable all-pass sections, each employing single FDCCII, two resistors and one capacitor. The salient features of all the proposed circuits are high input and low output impedance, single active element and use of grounded passive components. The proposed circuits with grounded components in each case are suited for IC implementation in CMOS technology. Non-ideality aspects and parasitic effects are also studied. The circuits are verified through PSPICE simulations using TSMC $0.35 \mu \mathrm{m}$ CMOS parameters. Application example in the form of multiphase oscillator is also given and also verified with good results. The proposed circuits are ideal for voltage-mode applications as well as good for IC implementation, making them a future prospect for integration.

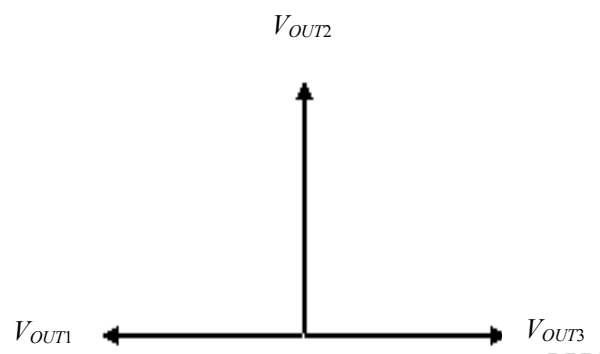

Figure 10. Phasor diagram of multiphase oscillator.

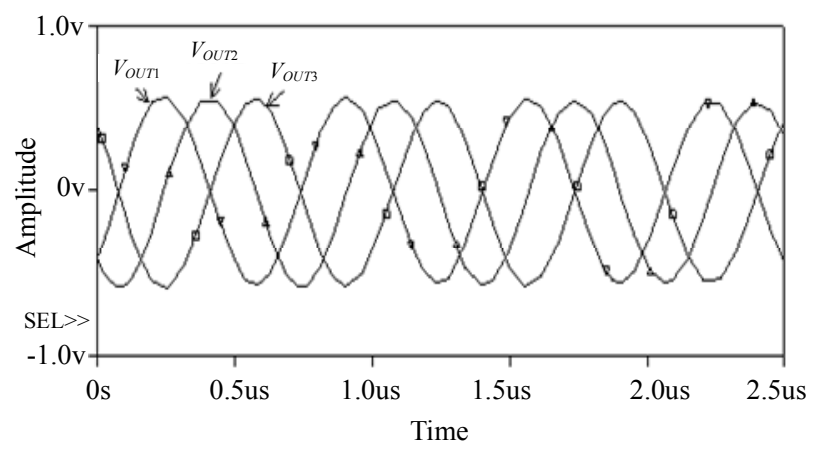

Figure 11. Quadrature voltage outputs of multiphase oscillator.

\section{Acknowledgements}

The authors would like to thank the anonymous reviewers for their valuable comments.

\section{References}

[1] M. Bhusan and R. W. Newcomb, "Grounding of Capacitors in Integrated Circuits," Electronics Letters, Vol. 3, No. 4, 1967, pp. 148-149.

[2] D. Biolek, R. Senani, V. Biolkova and Z. Kolka, "Active Elements for Analog Signal Processing: Classification, Review, and New Proposals," Radioengineering, Vol. 17, No. 4, 2008, pp. 15-32.

[3] S. J. G. Gift, "The Application of All-Pass Filters in the Design of Multiphase Sinusoidal Systems," Microelectronics Journal, Vol. 31, No. 1, 2000, pp. 9-13.

[4] A. M. Soliman, "Inductorless Realization of an All-Pass Transfer Function Using the Current Conveyor," IEEE Transactions on Circuits Theory, Vol. 20, 1973, pp. 80-81.

[5] A. M. Soliman, "Generation of Current Conveyor-Based All-Pass Filters from Op Amp-Based Circuits," IEEE Transactions on Circuits and Systems II: Analog and Digital Signal Processing, Vol. 44, No. 4, 1997, pp. 324-330.

[6] M. Higashimura and Y. Fukui, "Realization of All-Pass Network Using a Current Conveyor," International Journal of Electronics, Vol. 65, No. 22, 1988, pp. 249-250.

[7] O. Cicekoglu, H. Kuntman and S. Berk, "All-Pass Filters Using a Single Current Conveyor," International Journal of Electronics, Vol. 86, No. 8, 1999, pp. 947-955.

[8] I. A. Khan and S. Maheshwari, "Simple First Order AllPass Section Using a Single CCII," International Journal of Electronics, Vol. 87, No. 3, 2000, pp. 303-306.

[9] A. Toker, S. Özcan, H. Kuntman and O. Çiçekoglu, "Supplementary All-Pass Sections with Reduced Number of Passive Elements Using a Single Current Conveyor," International Journal of Electronics, Vol. 88, No. 9, 2001, pp. 969-976.

[10] M. A. Ibrahim, H. Kuntman and O. Cicekoglu, "FirstOrder All-Pass Filter Canonical in the Number of Resistors and Capacitors Employing a Single DDCC," Circuits, Systems, and Signal Processing, Vol. 22, No. 5, 2003, pp. 525-536.

[11] N. Pandey and S. K. Paul, "All-Pass Filters Based on CCII- and CCCII-," International Journal of Electronics, Vol. 91, No. 8, 2004, pp. 485-489.

[12] K. Pal and S. Rana, "Some New First-Order All-Pass Realizations Using CCII," Active and Passive Electronic Component, Vol. 27, No. 2, 2004, pp. 91-94.

[13] S. Maheshwari, I. A. Khan and J. Mohan, "Grounded Capacitor First-Order Filters Including Canonical Forms," Journal of Circuits, Systems and Computers, Vol. 15, No. 2, 2006, pp. 289-300.

[14] J. W. Horng, C. L. Hou, C. M. Chang, Y. T. Lin, I. C. 
Shiu and W. Y. Chiu, "First-Order All-Pass Filter and Sinusoidal Oscillators Using DDCCs," International Journal of Electronics, Vol. 93, No. 7, 2006, pp. 457-466.

[15] S. Minaei and O. Cicekoglu, "A Resistorless Realization of the First Order All-Pass Filter," International Journal of Electronics, Vol. 93, No. 3, 2006, pp. 177-183.

[16] H. P. Chen and K. H. Wu, "Grounded Capacitor First Order Filter Using Minimum Components," IEICE Transactions on Fundamentals of Electronics Communications and Computer Science, Vol. E89-A, No. 12, 2006, pp. 3730-3731.

[17] S. Maheshwari, "High Input Impedence VM-APSs with Grounded Passive Elements," IET Circuits Devices and Systems, Vol. 1, No. 1, 2007, pp. 72-78.

[18] S. Maheshwari, "High Input Impedance Voltage Mode First Order All-Pass Sections," International Journal of Circuit Theory and Application, Vol. 36, No. 4, 2008, pp. 511-522.

[19] S. Maheshwari, "Analog Signal Processing Applications Using a New Circuit Topology," IET Circuits Devices Systems, Vol. 3, No. 3, 2009, pp. 106-115.

[20] B. Metin and O. Cicekoglu, "Component Reduced AllPass Filter with a Grounded Capacitor and High Impedance Input," International Journal of Electronics, Vol. 96, No. 5, 2009, pp. 445-455.

[21] D. Biolek and V. Biolkova, “Allpass Filter Employing one Grounded Capacitor and one Active Element," Electronics Letters, Vol. 45, No. 16, 2009, pp. 807-808.

[22] D. Biolek and V. Biolkova, "First Order Voltage-Mode All-Pass Filter Employing One Active Element and One Grounded Capacitor," Analog Integrated Circuit and Signal Processing, Vol. 45, No. 16, 2009, pp. 807-808.

[23] T. Tsukutani, H. Tsunetsugu, Y. Sumi and N. Yabuki, "Electronically Tunable First-Order All-Pass Circuit Employing DVCC and OTA," International Journal of Electronics, Vol. 97, No. 3, 2010, pp. 285-293.

[24] S. Minaei and E. Yuce, "Novel Voltage-Mode All-Pass Filter Based on Using DVCCs," Circuits, Systems, and Signal Processing, Vol. 29, No. 3, 2010, pp. 391-402.

[25] A. A. El-Adway, A. M. Soliman and H. O. Elwan, "A Novel Fully Differential Current Conveyor and its Application for Analog VLSI," IEEE Transactions on Circuits and Systems II: Analog and Digital Signal Processing, Vol. 47, No. 4, 2000, pp. 306-313.

[26] C. M. Chang, B. M. Al-Hashimi, C. I. Wang and C. W. Hung, "Single Fully Differential Current Conveyor Biquad Filters," IEE Proceedings on Circuits, Devices and Systems, Vol. 150, No. 5, 2003, pp. 394-398.

[27] J. W. Horng, C. L. Hou, C. M. Chang, H. P. Chou, C. T. Lin and Y. Wen, "Quadrature Oscillators with Grounded Capacitors and Resistors Using FDCCIIs," ETRI Journal., Vol. 28, No. 4, 2006, pp. 486-494. 